\title{
The global governance of crisis migration
}

\section{Alexander Betts}

There is no coherent or unified global governance framework for the different areas that have been subsumed under the umbrella of 'crisis migration'. This is not to say that when new challenges or labels arise new institution-building is necessarily required. Addressing emerging protection gaps such as those related to crisis migration requires creativity in making existing institutions work better across implementation, institutionalisation and international agreements.

Given that there are significant protection gaps for different groups of vulnerable migrants affected by crises, to what extent are new international institutions required to address these gaps? Alternatively, is it realistic to believe that existing norms and international organisations might adapt or stretch to fill these gaps and address the emerging challenges, without the need for root and branch reform? Two simple concepts - 'regime complexity' and 'regime stretching' - can help us think about how existing institutions can adapt to new challenges.

\section{Regime complexity}

The concept of 'regime complexity' refers to the way in which institutions may be nested (part of a wider framework), parallel (having obligations in similar areas) and overlapping (with multiple institutions having authority over the same issue). ${ }^{1}$ This concept tries to make sense of the way in which international institutions have proliferated and highlights the way in which an issue may be governed by a disparate range of institutions. It is especially useful for understanding how 'new' and emerging areas are implicitly subject to the governance of multiple, overlapping institutions. Indeed, the regime complex for crisis migration straddles institutions from across a number of policy fields: migration, human rights, development, security governance and humanitarian. ${ }^{2}$

Identifying regime complexity has a host of international public policy implications. First, it gives rise to the recognition of implicit forms of governance. Second, it highlights how some policy areas may be simultaneously governed by multiple regimes in ways that 
may lead to either overlaps or gaps. Third, where there are gaps or overlaps these may create a case for improved coordination mechanisms. These and other challenges are likely to characterise the governance of crisis migration within which - with the exception of the refugee field - no international organisation or regime enjoys de facto exclusive lead status. Many of the constitutive areas of crisis migration are organisationally characterised by ad hoc responses - that is, beyond refugee protection for those fleeing state persecution, there is enormous inconsistency in responses to crisis migration.

Each of the areas subsumed under the umbrella of crisis migration - cross-border displacement caused by serious human rights deprivations that fall outside the dominant interpretation of persecution (what I have called elsewhere 'survival migration' ${ }^{3}$ ), 'trapped' or involuntarily immobile populations, anticipatory movements, and 'mixed migration' - are all subject to different implicit governance structures. In some cases these structures will adapt, or have the potential to adapt, to address formal 'gaps'. Survival migration, for instance, is subject to governance by the refugee regime, the human rights framework, humanitarian response, as well as emerging networks such as the Nansen Initiative. In recognising implicit regime complexes, we need to consider how far existing governance can fill gaps.

\section{Regime stretching}

The concept of 'regime stretching' helps to answer that question. It highlights the way in which a regime may adapt at the national level of implementation, even in the absence of adaptation at the levels of international negotiation or institutionalisation. This is a particularly important concept in a world in which new problems and challenges are emerging but where new formal institutions are created at a much slower pace. As problems emerge that were not within the scope of a regime at its creation, the norms and organisations may adapt (even without formal re-negotiation) not only through international bargaining or institutionalisation but also, at the level of implementation, through 'regime stretching'. Such institutional change not only occurs over time but can have different national manifestations at the same time.

Three recent cases of governance response are examples of whether and to what extent existing regime complexes are able to respond to the different sub-elements of crisis migration - and the extent to which regime stretching has taken place within the different areas: survival migration in the Horn of Africa in 2011, stranded migrants in Libya in 2011, and the combination of mixed migration, anticipatory movement and survival migration in Zimbabwe between 2006 and 2011. Each case reveals that in some areas existing institutions are functioning to address aspects of crisis migration but that more can be done to make existing institutions work better.

In the case of displacement resulting from the drought and famine in the Horn of Africa in 2011, the ability to link crisis migration to the refugee regime - because of the nature of refugee legislation and policy within Kenya and Ethiopia - meant that crisis migrants could fall within the mandate of UNHCR and so fleeing Somalis were able to receive protection as though they were refugees. While this enabled the refugee regime to stretch to address those fleeing the drought and famine, it has, however, strained the refugee regime almost to breaking point and even led to proposals for the creation of 'safe havens' within Somalia as an internal flight alternative.

In Libya in 2011, the situation of stranded migrant workers posed a challenge to governance that fell largely outside of established institutional responses. However, although based on an ad hoc response, the UNHCR-IOM cooperation on a joint Humanitarian Evacuation Cell in Geneva is a compelling source of future good practice for addressing the humanitarian needs of stranded migrant workers. With both Libyans and foreign migrants fleeing political instability, their exact status was ambiguous in the absence of refugee status determination. 
Nevertheless, they were registered and given a de facto form of temporary protection at the Egyptian and Tunisian borders.

The relatively limited number of people who attempted to cross the Mediterranean into Europe as a result of the conflict led to political tension over burden-sharing within the European Union (EU) and challenges to the Schengen Agreement on freedom of movement within the EU. In theory, regional governance in Europe should have offered temporary protection and related burden-sharing to protect people fleeing Libya. In practice, however, political divisions made implementation impossible.

Zimbabwe from 2006-11 was characterised by a form of 'mixed migration' insofar as the movements involved a complex array of motives and circumstances, and also included a significant number of anticipatory movements, with people leaving in large numbers prior to the elections in 2008, for example, in anticipation of significant violence. Many of those fleeing could also be classified as 'survival migrants', falling outside the framework of the 1951 Convention but still fleeing serious human rights deprivations and in need of international protection.

Neighbouring South Africa allowed all Zimbabweans access through 'asylumseeker permits', letting them self-settle with the right to work, pending assessment of their asylum claim. However, until 2009 the refugee recognition rate for Zimbabweans was extremely low and once Refugee Status Determination was complete, the Zimbabweans were open to arrest, detention and deportation. After April 2009, there were some attempts to adapt policy and the application of existing legislation; the possibility of applying the broader refugee definition contained in the OAU Refugee Convention covering events which "seriously disturb or disrupt public disorder" in the country of origin was mooted, for example.

The protection of Zimbabweans in South Africa has fallen between the cracks of different international organisations' mandates. UNHCR has consistently regarded most Zimbabweans as not being refugees;

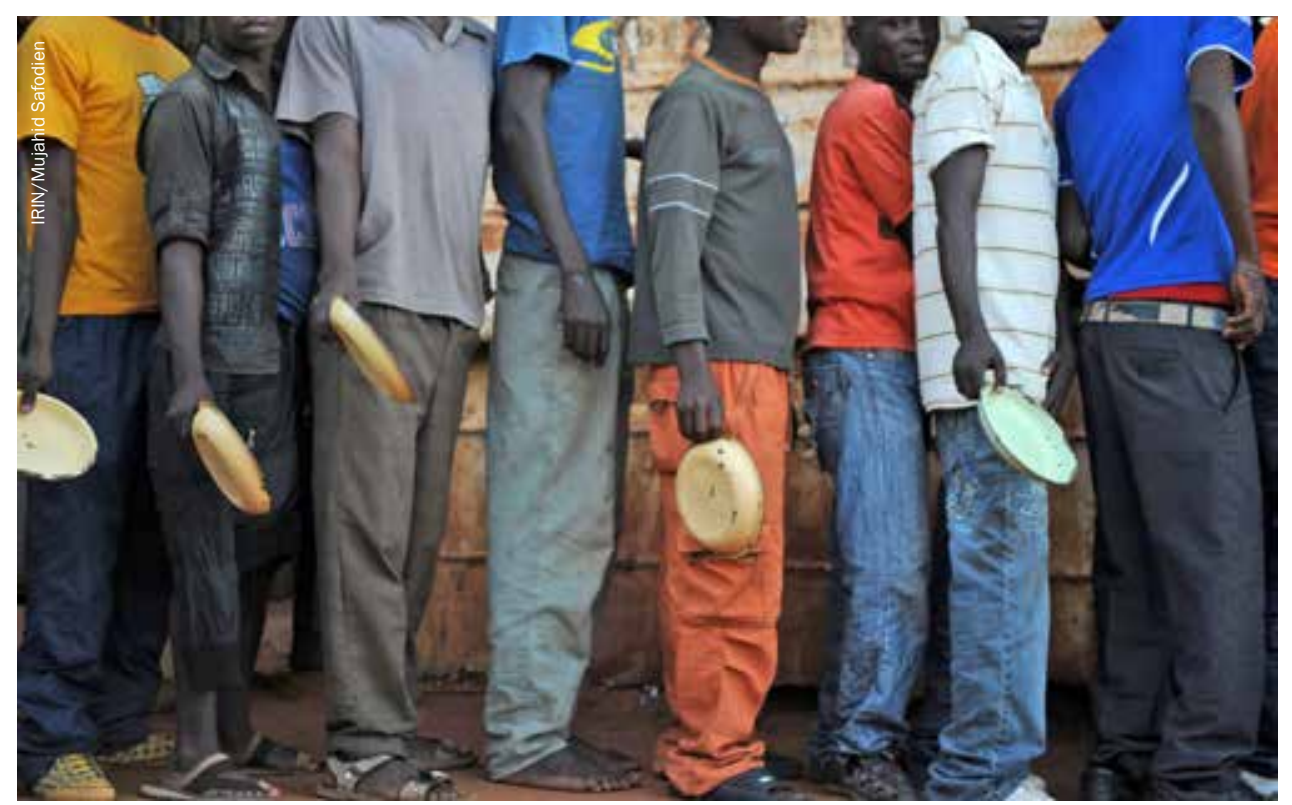

Migrants and asylum seekers at the 'I believe in Jesus Church' shelter for men in the South African border town of Musina queue up for a free hot meal, provided by UNHCR. 
only the granting of asylum-seeker permits to all who request them has put Zimbabweans within the purview of UNHCR's mandate. The most relevant sources of protection for many Zimbabweans have been local NGOs, church organisations and diaspora organisations. Community-based selfprotection strategies have filled some of the gaps left by the absence of adequate international or national-level responses.

In summary, the Horn of Africa case shows how, when there is a link to national refugee legislation, the refugee regime may stretch to cover gaps. In contrast, Libya highlights how the challenge of trapped and stranded migrant workers has required new and creative responses. Meanwhile, the Zimbabwean case shows how, when existing institutions have largely failed to adapt to complex mixed migratory movements, a range of informal structures and community-based self-protection mechanisms have filled some of the gaps.

\section{Policy}

These cases highlight the variability that exists in the extent to which existing institutions are or are not fit for purpose in relation to the challenges posed by different aspects of crisis migration. In some areas, existing governance structures adequately address the humanitarian challenge. In other areas, structures exist in theory but there are problems of implementation in practice. In still other areas, there are gaps that need to be filled.

An important analytical feature of many 'new' trans-boundary problems that emerge and require international cooperation is that they relate to and touch upon the purview of a set of norms and organisations that already exist, even if the relationship is not explicit. Crisis migration is one such area that is implicitly embedded within a pre-existing set of institutions. In such a situation, it makes sense to begin with a principle of making existing institutions work better. At the level of implementation, a range of norms and structures exists; these have been signed and ratified by states, even if they are not always fully implemented. Furthermore, states have signed up to and ratified human rights norms which have significant implications for how they should respond to crisis migration.

At the level of institutionalisation, there are ways in which existing norms or practices might be better incorporated within legal and policy frameworks. For example, the UN Convention on the Rights of All Migrant Workers and their Families has potential implications for the rights of stranded migrant workers in the context of crisis.

\section{At the level of international agreements,} once the possibility of improving existing institutions is exhausted, reforming international agreements need not imply the creation of new treaties or organisations. Instead, it may involve processes of consolidation in relation to existing norms and processes of coordination in relation to existing institutions. Soft-law frameworks may offer a means to provide an authoritative and applied consolidation of existing legal and normative standards. Similarly, when issue areas are embedded within organisational frameworks, creating improved coordination structures may help fill gaps.

The existing global governance framework for crisis migration can be understood as a regime complex, that exists at the global level in terms of the range of norms and international organisations of actual and potential relevance to addressing crisis migration. However, it also exists at the level of practice, where the implementation of the complex may have different manifestations in relation to different crises in different places.

Alexander Betts alexander.betts@qeh.ox.ac.uk is Associate Professor in Refugee Studies and Forced Migration at the Refugee Studies Centre, University of Oxford. www.rsc.ox.ac.uk

\footnotetext{
1. Alter, KJ and Meunier S (2009) 'The Politics of International Regime Complexity', Perspectives on Politics 7(1): 13-24.

2. See article by Jane McAdam, p10-11.

3. Betts A (2013) Survival Migration: Failed Governance and the Crisis of Displacement. Cornell University Press.
} 